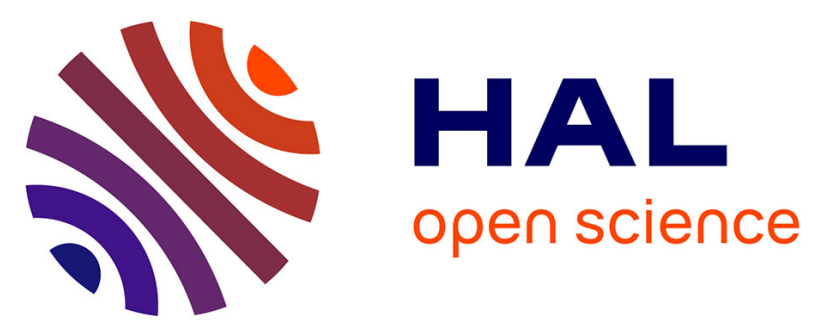

\title{
Pulmonary hyalinizing granuloma: a multicenter study of 5 new cases and review of the 135 cases of the literature
}

\author{
Raphael Lhote, Julien Haroche, Loïc Duron, Nicolas Girard, Marie Pierre \\ Lafourcade, Michel Martin, Hugues Begueret, André Taytard, Frédérique \\ Capron, Philippe Grenier, et al.
}

\section{To cite this version:}

Raphael Lhote, Julien Haroche, Loïc Duron, Nicolas Girard, Marie Pierre Lafourcade, et al.. Pulmonary hyalinizing granuloma: a multicenter study of 5 new cases and review of the 135 cases of the literature. Immunologic Research, 2016, 65 (1), pp.375-385. 10.1007/s12026-016-8852-4 . hal01527328

\section{HAL Id: hal-01527328 \\ https://hal.sorbonne-universite.fr/hal-01527328}

Submitted on 24 May 2017

HAL is a multi-disciplinary open access archive for the deposit and dissemination of scientific research documents, whether they are published or not. The documents may come from teaching and research institutions in France or abroad, or from public or private research centers.
L'archive ouverte pluridisciplinaire HAL, est destinée au dépôt et à la diffusion de documents scientifiques de niveau recherche, publiés ou non, émanant des établissements d'enseignement et de recherche français ou étrangers, des laboratoires publics ou privés. 
Pulmonary hyalinizing granuloma: a muticenter study of 5 new cases and review of the 135 cases of the literature

Running title: Pulmonary hyalinizing granuloma

Raphael Lhote ${ }^{1}, \mathrm{MD}$, Julien Haroche ${ }^{1,2}, \mathrm{MD}, \mathrm{PhD}$, Loïc Duron ${ }^{1}, \mathrm{MD}$, Nicolas Girard ${ }^{3}$, MD, PhD, Marie Pierre Lafourcade ${ }^{4}, \mathrm{MD}$, Michel Martin ${ }^{4}, \mathrm{MD}$, Hugues Begueret ${ }^{5}, \mathrm{MD}$, André Taytard $^{6}, \mathrm{MD}, \mathrm{PhD}$, Frédérique Capron ${ }^{2,7}, \mathrm{MD}, \mathrm{PhD}$, Philippe Grenier ${ }^{2,9}$, MD, PhD, Jean Charles Piette $^{1,2}$, MD, Fleur Cohen-Aubart ${ }^{1,2}$, MD, PhD and Zahir Amoura ${ }^{1,2}$, MD, MSc

(1) Service de Médecine Interne 2, Centre National de Référence Maladies autoimmunes Systémiques Rares, AP-HP, Groupe Hospitalier Pitié-Salpêtrière, Paris 75013, France

(2) Université Pierre et Marie Curie, Paris VI, Sorbonnes Universités, Paris 75013, France

(3) Service de Pneumologie, Centre National de Référence des Maladies Pulmonaires Rares Centre Expert National associé du Réseau RYTHMIC Tumeurs Thymiques et Cancer, Hôpital Louis Pradel, Lyon, France

(4) Service de Pneumologie, Centre Hospitalier d'Angoulême, Angoulême, France

(5) Service d'Anatomo-pathologie, Centre Hospitalier de Pessac, Pessac, France

(6) Service de Pneumologie, Centre Hospitalier de Pessac, Pessac, France

(7) Service d'Anatomo-pathologie, AP-HP, Groupe Hospitalier Pitié Salpêtrière, Paris, France

(8) Service de Radiologie, AP-HP, Groupe Hospitalier Pitié Salpêtrière, Paris, France

Correspondance to

Dr. Fleur COHEN AUBART

Service de Médecine Interne 2

Groupe Hospitalier Pitié-Salpêtrière

47-83 Boulevard de l'Hôpital 75651 PARIS CEDEX 13

France

fleur.cohen@psl.aphp.fr

Tél : + 33142178242

Fax : + 33142165804

No financial support was received

There is no conflicts of interest from the authors for the subject

Word count in abstract: 296

Word count in whole text:

Number of Tables: 4

Number of Figures: 6

Number of references: 82

Keywords : hyalinizing granuloma, lung nodule, 18FDG-TEPscan

Highlights

- $P H G$ is a rare and benign lung disease mimicking neoplasma

- $P H G$ is frequently associated with autoimmune, infectious or tumoral lesion that makes the prognosis 
- When PHG is symptomatic, corticosteroids are probably efficient to improve symptoms and nodule size 


\section{Abstract}

Background: Pulmonary hyalinizing granuloma $(\mathrm{PHG})$ is a rare disease characterized by single or multiple benign lung nodules mimicking lung neoplasma. Histologic analysis reveals homogenous hyaline lamellae, usually surrounded by collection of plasma cells, lymphocytes and histiocytes in a perivascular distribution. The clinical and radiological findings have been described in small series but the long-term outcomes have rarely been reported. The objectives were to describe the clinical, radiological and outcomes of PHG in new cases and through a literature review.

Patients and Methods: Patients with PHG were found by a multicenter search among French departments of internal medicine, pulmonology and anatomo-pathology. Review of the literature was made through the National Library of Medicine's MEDLINE database using key words "hyalinizing granuloma".

Results: Five news cases and 135 cases of the literature were found. There were 82 men and 57 women, mean age at the diagnosis 44.6 years (15-83). Patients were frequently asymptomatic $(n=39,27.4 \%)$. The nodule was unique in 37 cases $(28.9 \%)$ and multiple in 91 cases $(71.1 \%)$. 18FDG PET scan revealed hypermetabolism of the nodule in $9 / 15$ cases (60\%). A systemic disease was associated in 65 cases (mainly mediastinal and retroperitoneal fibrosis, autoimmune, tumoral or infectious disease or thromboembolism). The outcomes were evaluated in 73 patients when follow-up was available: 14 patients had a surgical resection of the nodule. Forty-five patients did not receive any immunosuppressive drug. Among these patients, 2 improved, 29 were stable and 14 worsened. Corticosteroids were used as a monotherapy in 19 patients and led to radiological improvement in 8 cases, stabilization in 8 cases and worsening in 3 cases. 5 patients were treated with corticosteroids and at least one immunosuppressive drug and 4 patients improved.

Conclusion: $\mathrm{PHG}$ is a rare benign disease, mimicking lung neoplasma, frequently associated with systemic diseases. 


\section{Abbreviations}

- BAL : broncho-alveolar lavage

- CT scan: Computerized tomography scanner

- FEV1: forced expiratory volume in one second

- FVC: forced vital capacity

- HBV: hepatitis B virus

- HCV: hepatitis C virus

- HIV: human immunodeficiency virus

- MALT: mucosa-associated lymphoid tissue

- PHG: pulmonary hyalinizing granuloma

- SUV: standard uptake value

-18FDG PET: 18 fluorodesoxyglucose positron emission tomography 


\section{Introduction}

Pulmonary hyalinizing granuloma $(\mathrm{PHG})$ is a rare disease, which was first reported by Benfield ${ }^{1}$ in 1964 then characterized by Engleman in $1977^{2}$. PHG is characterized by single or multiple benign nodules found in the lungs and is frequently asymptomatic. The diagnosis relies on histological analysis, which shows homogenous hyaline lamellae usually surrounded by collection of plasma cells, lymphocytes and histiocytes in a perivascular distribution ${ }^{2}$. This histologic pattern has also been described in isolated extra respiratory localizations ${ }^{3}$. PHG may be associated with mediastinal and retroperitoneal fibrosis, autoimmune, hematologic, thrombo-embolic and infectious diseases. Physiopathology is still unclear, but the association with inflammatory diseases evokes an immune pro-inflammatory pathway.

The prevalence of PHG has been estimated in two papers. In 1980 Ulbright reported 2 cases of PHG in a population of 86 patients with solitary necrotic granuloma of the lung ${ }^{4}$. In 2012 Peng reported 1 case of PHG in a population of 481 patients with diffuse parenchymal lung disease ${ }^{5}$.

Here we report 5 new cases of PHG and provide an exhaustive review of all cases reported in the literature, focusing on clinical presentation, diagnosis modalities, treatment response, long-term outcomes and associated-diseases.

\section{PATIENTS AND METHODS}

\subsection{Patients' selection}

After interrogation of French internal medicine physicians, chest physicians and pathologists, ten patients with PHG were identified. The diagnosis was confirmed by histology in all cases. In 5 cases, medical data were insufficient. Data were extracted from medical records and demographic, clinical, biological and radiographic data were collected. Histology was reviewed when available by a pathologist with a strong experience in lung disease especially 
PHG (FC). Because PHG may be associated with mediastinal a retroperitoneal fibrosis and that one case was previously reported associated with hyperlgG4, the available cases (case 1 and case 2) were stained with an anti IgG4 antibody according to manufacturer instructions.

\subsection{Literature review}

We searched through the National Library of Medicine's MEDLINE database for relevant literature using the key words "hyalinizing granuloma". The references of selected articles were reviewed for additional cases reports. We found 135 patients from $80^{1-2,4,6-82}$ articles between 1964 and 2015 in the English, French, Spanish, Italian, German, Turk, Polish, Chinese and Japanese literature.

The demographic and clinical characteristics, diagnosis modalities, associated diseases and biological results were collected.

\subsection{Follow-up and outcomes}

The treatments were collected for all cases when available. The primary end-point was the radiological evolution of the nodule at last visit. For the literature cases, the radiological outcome (stable, improved or worsened) was noted from the papers.

\subsection{Statistical analysis}

The statistical analysis was performed with GraphPad V6.0 (San Diego, CA). The qualitative data were described with percentages. The quantitative data were reported with median or mean when appropriate and range. The outcomes for patients treated and not treated were compared with Fisher's exact test. All tests were bilateral and $p$-values $<0.05$ were considered as statistically significant.

\section{RESULTS}

\subsection{Reported cases}


Clinical, biological and radiological findings of reported cases are presented in Table 1, figure 1 à 4 . Median time of follow up were 153.6 month.

There were 4 males and 1 woman, with a median age at diagnosis of 48.8 years (22 to $62 y$ o). Immulogic diseases were associated in two patients (grave's disease and sarcoidosis). Other disease were found diabetes mellitus $(n=1)$, sinusitis, nasal polyposis $(n=1)$ and asbestos exposure $(n=2)$, high blood pressure $(n=1)$, basocellular carcinoma $(n=1)$, liver transplantation for post alcoholic cirrhosis $(n=1)$. Tabaco use status was known in 3 case and present in one case $(33 \%)$

Two patients were asymptomatic, one present dyspnoea (due to pulmonary embolism once and to pneumothorax second), two patients presents mediastinal fibrosis with loss of weight and dysphagia (one 10 years after diagnosis of asymptomatic lung calcificated nodule, and one concomitant of diagnosis of PHG). Radiological findings found nodular lung lesions unique $(n=2)$ and multiple $(n=3)$ with a size between 70 and $90 \mathrm{~mm}$. One patient present interstitial lung disease associated. 18FDG PET was available and positive in 2 cases.

Diagnosis was made with wedge biopsy for 4 patients and lobectomy for 1 patient. CTguided percutaneous needle lung biopsy was realized once but results were not conclusive.

IgG4's syndrome was searched in two cases and was never found.

Biologic's data found an inflammatory syndrome in 50\% (elevated CRP in 2/4 cases), immunologic test were always negative $(n=3)$, hypereosinohilia $(n=1)$, there were no HIV, HCV or HBV infection.

Tuberculin skin test result was recorded in 2 cases: one negative and one phlyctenular, Histoplasmosis test was known and negative in one case. Sputum for mycobacterium tuberculosis were negative in two cases. 
Respiratory tests showed airway obstruction (FEV1/FVC 57\%, FEV1 71\%) with bronchial hyper-responsiveness $(n=1)$. Respiratory function displayed restrictive features $n=1$.

No more treatment was made, and follow up did not found evolution at 2 years for one patient. One patient present pulmonary embolism of the right proximal pulmonary artery and seven months later, a pneumothorax occurred; a corticosteroid treatment was introduced without improvement of lung nodule. Two patients were treated with corticosteroid and cyclophosphamide for associated mediastinal fibrosis with improvement of lung lesion but don't prevent death in one case after compression of cardiac cavity by fibrosis.

\subsection{Literature review}

We studied 135 patients from 80 articles between 1964 and 2015 in the English, French, Spanish, Italian, German, Turk, Polish, Chinese and Japanese literature.

\subsubsection{Demographic and clinical characteristics}

Demographic and clinical characteristics of all patients (our series and literature, $n=135$ ) are presented in Table 2.

The mean age at PHG diagnosis was 44.6 years (range: $15-83$ yrs). There was a male predominance (82 males/57 females); the sex was not reported in one observation. The ethnic group was known in 79 cases $(56.4 \%)$ of cases : european were predominant $(n=32$, $40.5 \%)$, followed by african or afroamerican $(n=19,24 \%)$, asiatic $(n=15,29.1 \%)$, arabs or middle east people $(n=11,13.9 \%)$ and indian $(n=2,2.5 \%)$. Thirty-one patients were active smokers $(31 / 52,59.6 \%)$ with a 32.5 pack-year median consummation.

The working activity was reported in 22 cases (15.1\%) and an environmental exposition was found in 14/22 cases (63.6 \%) (factory worker, maid, cement worker, chemistry industry, 
cotton industry, pet shop, old locomotive driver, mine worker). Asbestos exposure was reported in two of our patients.

The patients were asymptomatic in 38 observations (27.1\%). Respiratory symptoms were reported in 77 cases (55\%) with cough ( $n=44,31.4 \%)$, chest pain/pleural effusion $(n=29$, $20.7 \%)$, dyspnea $(n=29,20.7 \%)$ and hemoptysis $(n=11,7.9 \%)$. General symptoms were also reported with fever $(n=15,10.7)$, loss of weight $(n=13,9.3 \%)$, asthenia $(n=9,6.4 \%)$, night sweats $(n=5)$ and lymphadenopathy $(n=1)$.

Most of extra-respiratory symptoms were due to extra respiratory localizations of PHG and/or associated pathology (dysphagia, headache, diplopy, abdominal mass, cutaneous/mandibular localization, uveitis, etc...). Extra respiratory localizations of hyalinizing granuloma with histologic confirmation were $(n=19.13 .6 \%)$ : skin $(n=4)^{5,48,68,71}$, tonsillar or subglottic area $(n=3)^{2,14,35}$, pleural localization $(n=1)^{36}$, optic nerve $(n=1)^{66}$, pituitary gland $(n=1)^{66}$, liver $(n=1)^{\text {case } 1}$, joints $(n=1)^{35}$, spleen $(n=1)^{23}$, pericardium $(n=1)^{23}$, and abdominal mass $(\mathrm{n}=1)^{35}$.

\subsubsection{Pathological conditions associated with PHG}

Pathological conditions associated with PHG are presented in Table 3.

PHG was associated with an infection in 19 cases (14.1\%). Tuberculosis was the most common $(n=14)^{2,7,9,30,36,48,50,65,69,72,73,74}$. One case of infection with the Human Immunodeficiency virus (HIV) was reported in association with $\mathrm{PHG}^{65}$.

PHG was associated with an auto-immune disease in 17 cases (12.1\%): Grave's disease $(n=2 \text { including case } 1)^{43}$, sarcoidosis $(n=2 \text { including case } 4)^{75}$, cutaneous vasculitis $(n=2)^{2,6}$, antiphospholipid syndrome $(n=1)^{60}$, idiopathic thrombocytopenic purpura $(n=3)^{78,53,79}$, multiple sclerosis $(n=1)^{28}$, rheumatoid arthritis $(n=1)^{10}$, Riedel disease $(n=1)^{16}$, Sjögren syndrome $(n=1)^{82}$, auto-immune thyroïditis $(n=3)^{16}, \lg A$ nephropathy $(n=1)^{70}$, hyperlgG4 syndrome $(n=1)^{75}$ and ANCA associated vasculitis (micro polyangéitis and granulomatosis with 
polyangeitis $(n=2)^{2,82}$. Mediastinal fibrosis and retroperitoneal fibrosis were found in respectively $19^{2,10,12,13,14,19,22,23,43,59}$ (including cases \#1 and 2) and 12 cases $1,2,9,13,23,25,40,47,51,52,54,62$

PHG was associated with an hematological disease in 5 cases $(3.7 \%)$ : amyloidosis $(n=2)^{2,25}$, multiple myeloma, lymphoma and amyloidosis $(n=1)^{7}$, MALT lymphoma $(n=1)^{36}$ and Castleman's disease $(n=1)^{27}$.

PHG was associated with a solid tumor in 6 cases $(4.4 \%)$ : breast Paget disease $(n=1)^{18}$, lung adenocarcinoma $(n=1)^{2}$, meningioma $(n=1)^{60}$, anaplastic astrocytoma $(n=1)^{26}$, thyroid carcinoma $(n=1)^{73}$ and basocellular carcinoma $(n=1$, case 4$)$.

PHG was associated with thromboembolic disease in 8 cases: peripheral venous thrombosis $(n=4)^{25,49,60,69}$, ischemic cardiac disease $(n=2)^{32,34}$ pulmonary embolism $(n=1)^{\text {case } 4}$, stroke $(n=1)^{34}$. Other pathologies were reported but with no evidence of relationship with PHG (spontaneous echymosis, nasal polyposis, alcohol behavior (including 1 with liver transplantation), gout, adenomyosis.

\subsubsection{Radiological findings}

The results of thoracic imaging with chest $X$ ray or chest CT scan were reported in 138 cases. The most frequent finding was nodular lesions $(n=128,92.7 \%)$ isolated $(n=37$, $28.9 \%)$ or multiple $(n=91,71.1 \%)$, sometimes with excavation $(n=10,8.2 \%)$ and/or calcification ( $n=6,4.3 \%)$. The size of the nodules was reported in 77 cases $(60.2 \%)$. This size was between $1 \mathrm{~mm}$ and $10 \mathrm{~cm}$. Most of the nodules were between 1.5 and $5 \mathrm{~cm}(n=61$, $79.2 \%)$

In rare cases, a lung parenchymal infiltration or condensation was found, alone or in association with nodules. 
The 18FDG-PET scan results were reported in 15 cases. Nine patients $(60 \%)$ displayed hypermetabolism of the nodules, with standard uptake variation (SUV) ranging from 2.2 to 9.6.

\subsubsection{Biological characteristics}

The biological results were reported in 72 cases (49.6\%). A blood inflammatory syndrome was found in $30 / 55$ cases (54.5\%). Immunoglobulins levels were evaluated in 20 cases :

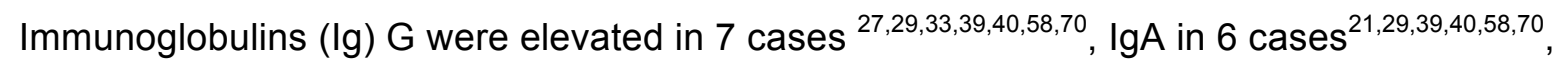
$\operatorname{lgM}$ in 4 cases $^{27,29,33,39}$, IgE in 4 cases $^{27,29,33,41}$ and subclass if IgG IgG4 in 2 cases $^{2,8}$. Blood standard tests were almost normal, excepted in cases with extra respiratory localizations (hypeprolactinemia ${ }^{66}$, elevated creatinin level ${ }^{1,40}$ ). Tumor markers were reported in 10 cases and were always negative.

The results of immunological tests were reported in 51 cases and were positive in 22 cases (43.1\%). Positivity was found for antinuclear antibodies $(n=11)^{6,8,14,39,50,60,70}$, antimicrosomal antibodies $(n=5)^{8,9,14,23,56}$, anti thyroglobulin antibodies $(n=3)^{9,23,56}$, Coombs test $(n=4)^{8,14}$, circulating immune complex $(n=4)^{8,11,20,27}$, rheumatoid factor $(n=2)^{8,50}$, lupus anticoagulant antibody $(n=2)^{49,60}$, anti smooth muscle cell antibodies $(n=2)^{8,14}$ and ACAN $(n=2)^{32,82}$. The tuberculin skin test results were reported in 46 cases and were positive in 20 (43.5\%). The histoplamosis skin test results were reported in 19 cases and were positive in 6 (31.6 \%). Histoplasme serology was always negative $(n=4)$. When BAL was realized, microbiological tests were always negative excepted in 2 cases (histoplasma $(n=1)^{68}$ and aspergillus $\left.(n=1)^{44}\right)$. In one case a typical histoplasomis granuloma was found ${ }^{10}$.

\subsubsection{Respiratory function}

The respiratory function was evaluated in 21 cases and was abnormal in 15 . Moderate obstructive syndrome was found in 12 cases and restrictive syndrome in 3 .

\subsubsection{Diagnosis, treatment and outcomes}


BAL and transbronchial biopsies never allowed achieving PHG diagnosis. CT-guided percutaneous needle lung biopsies were realized in 14 cases and were positive in 4 . Surgical biopsies (lobectomy or wedge resection) were reported in 108 cases. Diagnosis was made after autopsy in 5 cases. Only one case was not confirmed by histology.

Youssem and al reported 24 patients from whom follow up was completed in 19. Median follow-up was 36.8 months. All solitary nodules disappeared $(n=6)$. In cases of multiple nodules $(n=13), 6$ worsened and 7 remained stable.

The follow-up was reported in 73 others cases (62.9\%), with a median follow-up of 59 months (range: 1 month-39 years) (Figure 5)

Fourteen of 73 patients underwent a curative surgical resection of the nodules with a complete resection (19\%) (Table 4a). Among these 14 patients, recurrence of PHG occurred in 6 cases (46.2\%): 4 after lobectomy and 2 after wedge resection. Corticosteroids were given in 3 of 6 patients: one was lost to follow-up, radiological data was stable for one patient and improved for the other. One additional patient underwent surgery for recurrence and recurred a second time.

Fifty-nine of 73 patients (81\%) had a residual disease after diagnostic biopsy (Table 4b). Forty six patients $(63 \%)$ did not receive any medical treatment following diagnosis. Among these patients, the nodule size slowly increased in 15 cases $(32.6 \%)$, remained stable in 29 cases $(63 \%)$ and improved in 2 patients $(4.4 \%)$. Of note, among the 29 nodules that remained stable, one was evaluated with 18 FDG PET scan that showed a decrease of the nodule SUV. Among the 15 patients whom nodule size increased, 3 were treated with corticosteroids and 3 with an association of corticosteroids and other immunosuppressive and/or immuno-modulatory drug. Three patients improved with nodule size decreased (50\%), 2 stay stable (33.3\%) and one worsened (16.7\%). 
Allover, 19 patients were treated with corticosteroids therapy as a monotherapy, 13 patients in first intention and 6 patients after initial no treatment follow-up. Nodule size decreased in 8 cases $(42.1 \%)$, was stable in $8(42.1 \%)$ with decreased in SUV in 1 case and worsened in 3 cases $(15.8 \%)$.

In 5 cases, patients were treated with others therapies in addition to corticosteroids.

Corticosteroids were associated with cyclophosphamide in 2 patients for mediastinal fibrosis (leading to decrease of nodule size in these 2 cases), intravenous immunoglobulins, plasmatic exchange and corticosteroids for Morvan's syndrome in 1 patient with stable radiological lesion, melphalan, vincristine and corticosteroids for 1 patient with myeloma (leading to decrease in nodule size), with cyclophosphamide, vincristine and prednisone form MALT lymphoma for 1 patient (leading to decrease of nodule size).

Radiological improvement (decrease in size) of the nodules was more frequent in patients treated with corticosteroids than patients without treatment (respectively $42.1 \%$ and $4.4 \%$ ) with a statistically significant difference $(p=0.0006)$. (Figure 6 , table 4a)

Due to the hypothesis of an infectious disease associated to PHG, antibiotics, antifungal therapy and antitubercular drugs were given in several observations, but they were never effective.

Among the 135 cases, 9 patients died during follow-up (7\%). Two deaths ${ }^{38,67}$ were related to PHG. One of the patients died after 30 years of interstitial lung disease and PHG diagnosis was made after autopsy ${ }^{38}$. The second patient died after compression of the right cardiac cavity by a lung nodular lesion ${ }^{67}$. The other causes of deaths were infectious pneumonia $(n=4)^{26,34,52,60}$, acute hemolytic anemia $(n=1)^{10}$ refractory mediastinal fibrosis $(n=1$, case 1$)$ and myeloma $(n=1)^{7}$

\section{DISCUSSION}


PHG is a rare lung disease characterized by homogenous hyaline lamellae, usually surrounded by collection of plasma cells, lymphocytes and histiocytes in a perivascular distribution.

We identified 5 new patients with PHG and reviewed the 135 cases of the literature. According to our results, PHG is a rare disease typically occurring in Caucasian middle age men, frequently active smoker. PHG may be asymptomatic $(27.8 \%)$. In radiological explorations, nodules are isolated $(28.9 \%)$ or multiple $(71.1 \%)$ and are frequently in 18 FDG PET scan (60\%). The diagnosis of PHG is always confirmed by histology. CT-guided percutaneous needle biopsy seems to be effective in nodular lung disease ${ }^{5}$ but worst in PHG with diagnosis in $28.6 \%$ of the cases. When the diagnosis is not achieved, wedge resection leads to the diagnosis. When a wedge resection is not possible, lobectomy should be considered because of the risk of malignancy.

In the previously reported cases, PHG was often associated with mediastinal $(13.6 \%)$ or retroperitoneal $(8.6 \%)$ fibrosis, autoimmune $(12.1 \%)$, infectious $(13.6 \%)$ tumoral, haematological and thromboembolic diseases.

Due to the association with systemic fibrosis [83] and autoimmune disease, an immune abnormal reaction has been evoked to explain the PHG formation. Infectious trigger could alo be considered due to the association with some infectious diseases. This association between infection disease and autoimmune disease has been often suggested [84]. Despite the analysis of the literature, the physiopathology of PHG remains unclear and even if tuberculosis, auto-immune diseases and tumoral diseases seem to be frequently associated with PHG, they do not seem to be the cause of the disease. Due to association with systemic fibrosis, association with IgG4 syndrome was evoked and reports in one case, in our series no case of hyperlgG4 syndrome was found. 
Histology is necessary for diagnosis. Currently there is no imaging or metabolic test which allows to differentiate PHG from others diagnosis, especially lung neoplasma. As reported by Peng ${ }^{4}$ CT guided percutaneous needle biopsy should be efficient for lung disease diagnosis. Our analysis of the literature confirmed the efficiency of CT guided needle biopsy to diagnose PHG.

When the diagnosis is confirmed, these associated pathologies have to be searched because they are important for outcome, prognosis and therapy.

Outcome is often good. Corticosteroids may improve the natural evolution of PHG, but rarely necessary. PHG does not frequently cause the death of patients. The low evolution of this pathology allows an active follow up and permits a reduction of corticosteroid impregnation.

Conclusion

PHG is a rare disease with a good prognosis mimicking lung neoplasm. Diagnosis required invasive strategy for histology. This pathology usually does not need treatment but corticosteroids seem efficient when necessary. PHG is frequently associated with infectious, auto immune and neoplasm diseases which have to be search. These pathologies lead the prognosis and treatment is more associated to their presence than to respiratory symptoms of PHG. 


\section{Figures legends}

Figure 1: Chest CT scan of case \#2 showing multiple nodules (a) and mediastinal fibrosis (b)

Figure 2: Chest CT scan of case \#3 showing solitary nodule (a) and hypermatabolic 18FDGPET of case $3(b)$

Figure 3: Chest CT scan of case \#4 showing solitary nodule with associated interstitial lung disases(a) and hypermetabolic 18FDG-PET (b)

Figure 4: Chest CT scan of case \#5 showing multiple nodules

Figure 5: Outcomes in patients with PHG followed up

Figure 6: Outcomes in patients without treatment or receiving cosrticosteroids

\section{Tables legends}

Table 1: Clinical, biological and imaging features of the 5 new reported cases

FEV1: forced expiratory volume in 1 second, FVC: Forced vital capacity, VC: vital capacity, NA : non avalaible data

Table 2: Clinical characteristics of patients (reported cases and literature)

Table 3: Pathological conditions associated with PHG.

Table 4: Treatments and long-term outcomes 
Figures

Figure1:

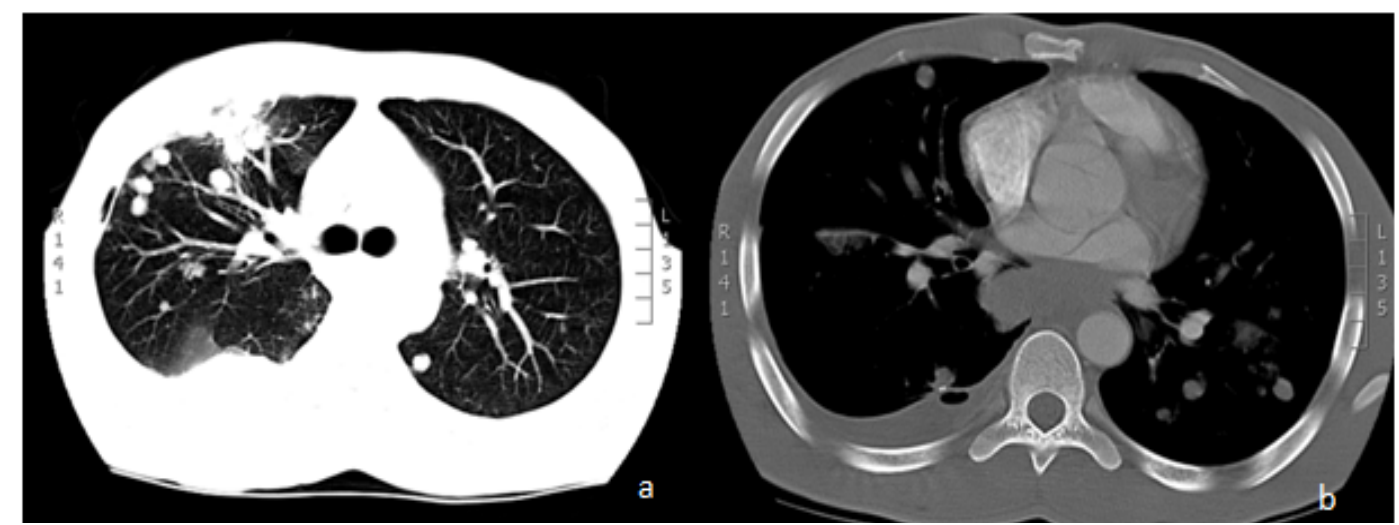

Figure 2:
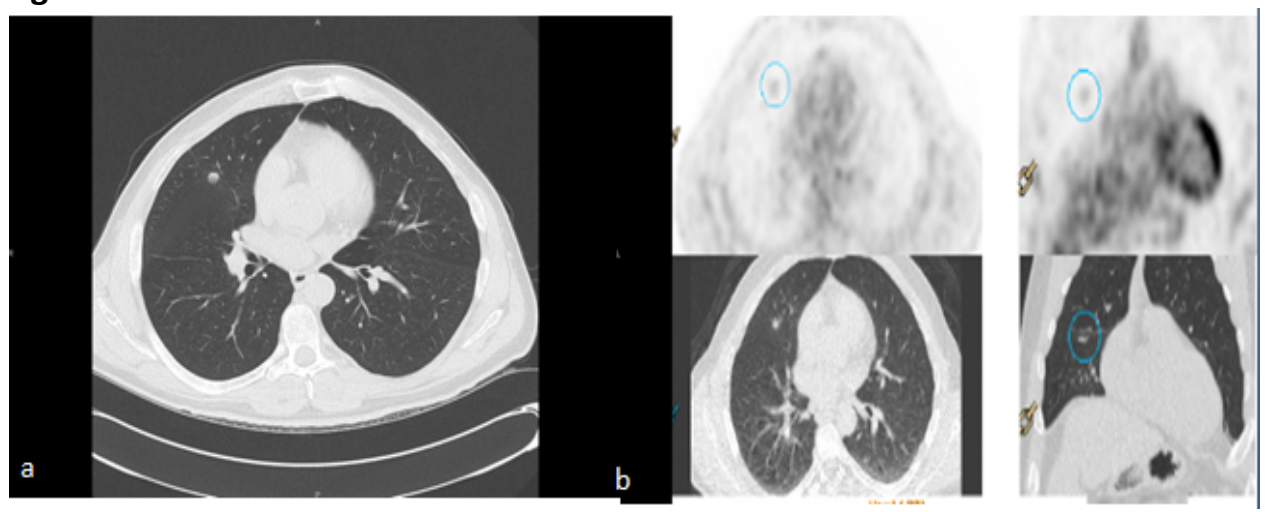

Figure 3:

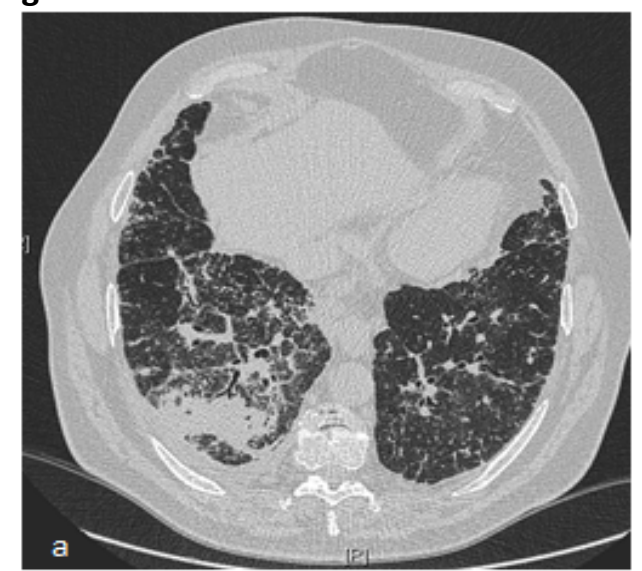

14 Study एృ! 4 Study Tirn

Figure 4

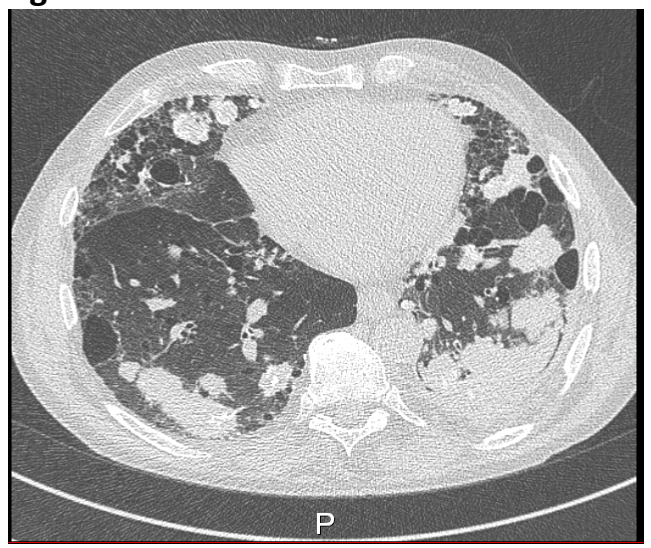


Figure 5

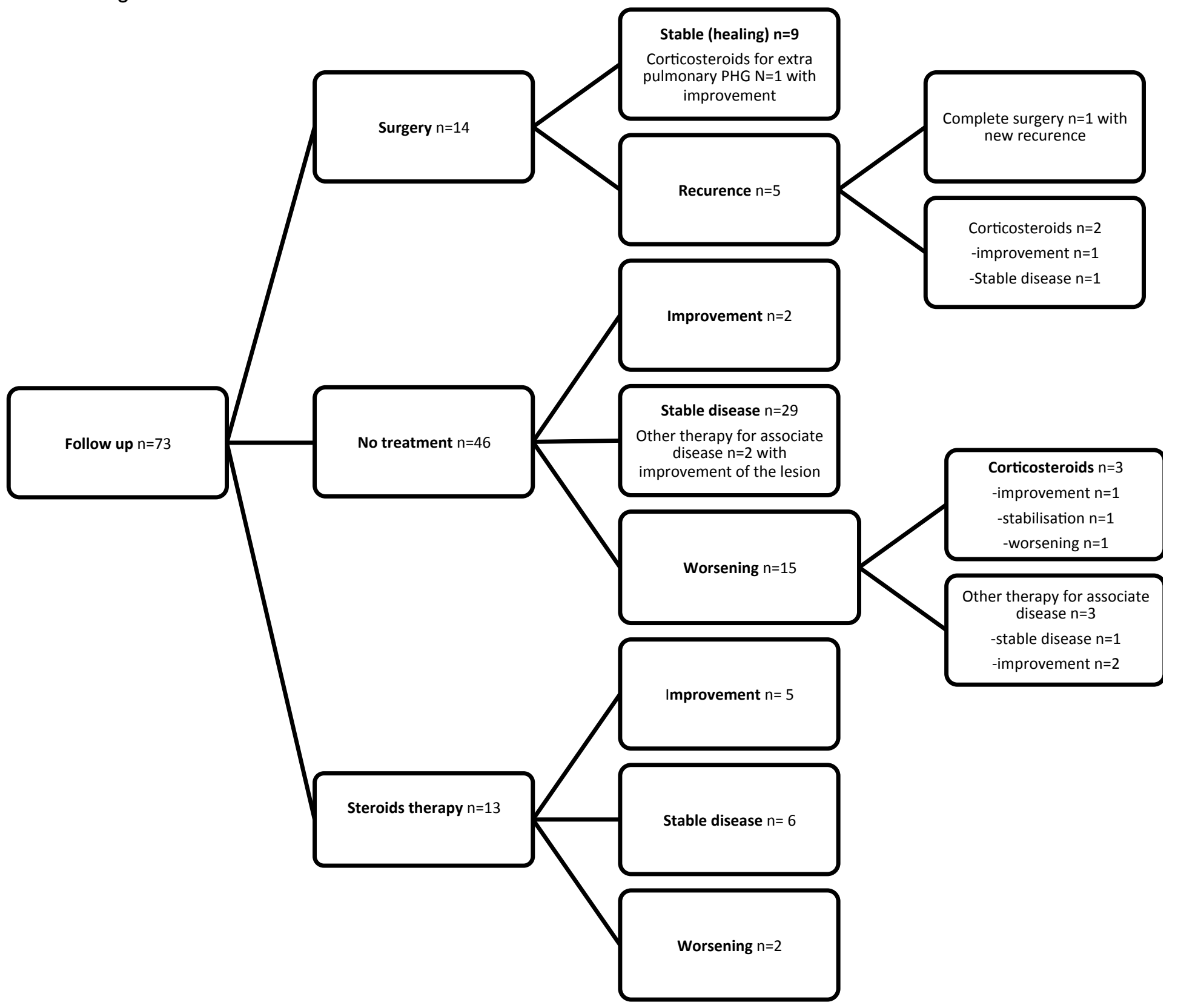


Figure 6

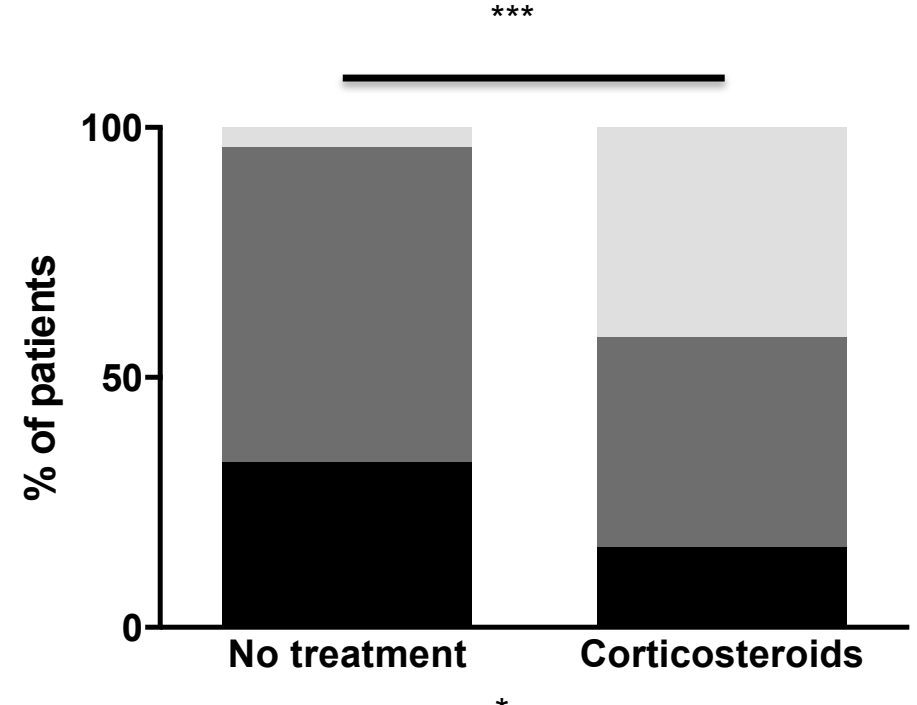


Table 1

\begin{tabular}{|c|c|c|c|c|c|}
\hline & Case \#1 & Case \#2 & Case \#3 & Case \#4 & Case \#5 \\
\hline Sex & Female & Male & Male & Male & Male \\
\hline Age (Years) & 57 & 22 & 55 & 62 & 55 \\
\hline $\begin{array}{l}\text { Respiratory } \\
\text { symptoms }\end{array}$ & 0 & 0 & 0 & Dyspnea & 0 \\
\hline Dysphagia & Present & Present & 0 & 0 & 0 \\
\hline Fever & 0 & 0 & 0 & 0 & 0 \\
\hline Loss of weigh & 0 & Present & 0 & 0 & 0 \\
\hline Tuberculine test & Negative & Phlyctenular & NA & NA & NA \\
\hline Hemogram & Normal & $\begin{array}{l}\text { Hyper- } \\
\text { eosinophilia }\end{array}$ & Normal & Normal & NA \\
\hline AAN & Negative & Negative & NA & Negative & NA \\
\hline $\begin{array}{ll}\text { CRP } & \text { level } \\
\text { (mg/liter) } & \end{array}$ & 28 & 80 & $<5$ & $<5$ & NA \\
\hline $\begin{array}{l}\text { Respiratory } \\
\text { function test }\end{array}$ & NA & Normal & $\begin{array}{l}\text { FEV1/NCL } \\
57 \% \\
\text { FEV1 } 71 \%\end{array}$ & VC $74 \%$ & NA \\
\hline Chest CT scan & $\begin{array}{l}\text { Multiples } \\
\text { nodules }\end{array}$ & $\begin{array}{l}\text { Multiple } \\
\text { nodules } \\
\text { mediastinal } \\
\text { fibrosis }\end{array}$ & $\begin{array}{l}\text { Solitary } \\
\text { Nodule }\end{array}$ & $\begin{array}{l}\text { Solitary } \\
\text { nodule }\end{array}$ & $\begin{array}{l}\text { Multiple } \\
\text { nodule } \\
\text { ILD }\end{array}$ \\
\hline 18FDG PET & NA & NA & $\begin{array}{l}\text { Hyper } \\
\text { metabolism }\end{array}$ & $\begin{array}{l}\text { Hyper } \\
\text { metabolism }\end{array}$ & NA \\
\hline
\end{tabular}


Table 2 :

\begin{tabular}{|c|c|c|c|}
\hline & Our series $(n=5)$ & Literature $(n=135)$ & All $(n=140)$ \\
\hline Age, years (range) & $48.8(22-62)$ & $44,5(15-83)$ & $44.6(15-83)$ \\
\hline Sex ratio : M/W & $4 / 1$ & $78 / 56$ & $82 / 57$ \\
\hline $\begin{array}{l}\text { Origin (caucasian/ } \\
\text { african and afro- } \\
\text { american/ arab and } \\
\text { middle } \\
\text { Asiatic/lndian) }\end{array}$ & NA & $79(32 / 19 / 11 / 15 / 2)$ & \\
\hline \multicolumn{4}{|l|}{$\begin{array}{l}\text { Clinical } \\
\text { characteristics }\end{array}$} \\
\hline Asymptomatic & $3(60 \%)$ & $36(26.6 \%)$ & $39(27.8 \%)$ \\
\hline $\begin{array}{l}\text { Respiratory } \\
\text { symptoms }\end{array}$ & 0 & $76(56.3 \%)$ & $77(55 \%)$ \\
\hline Cough & 0 & $44(32.6 \%)$ & $44(31.4 \%)$ \\
\hline Chest pain & 0 & $29(21.5 \%)$ & $29(20.7 \%)$ \\
\hline Dyspnea & 1 & $28(20.7 \%)$ & $29(20.7 \%)$ \\
\hline Haemoptysis & 0 & $11(8.1 \%)$ & $11(7.9 \%)$ \\
\hline \multicolumn{4}{|l|}{ General symptoms } \\
\hline Fever & $1(20 \%)$ & $14(10 \%)$ & $15(10.7 \%)$ \\
\hline Loss of weight & $1(20 \%)$ & $12(8.9 \%)$ & $13(9.3 \%)$ \\
\hline Dysphagia & $2(40 \%)$ & $6(4.4 \%)$ & $8(5.7 \%)$ \\
\hline Asthenia & 0 & $9(6.7 \%)$ & $9(6.4 \%)$ \\
\hline $\begin{array}{l}\text { Others localization of } \\
\text { PHG }\end{array}$ & 0 & $19(14 \%)$ & $19(13.6 \%)$ \\
\hline
\end{tabular}




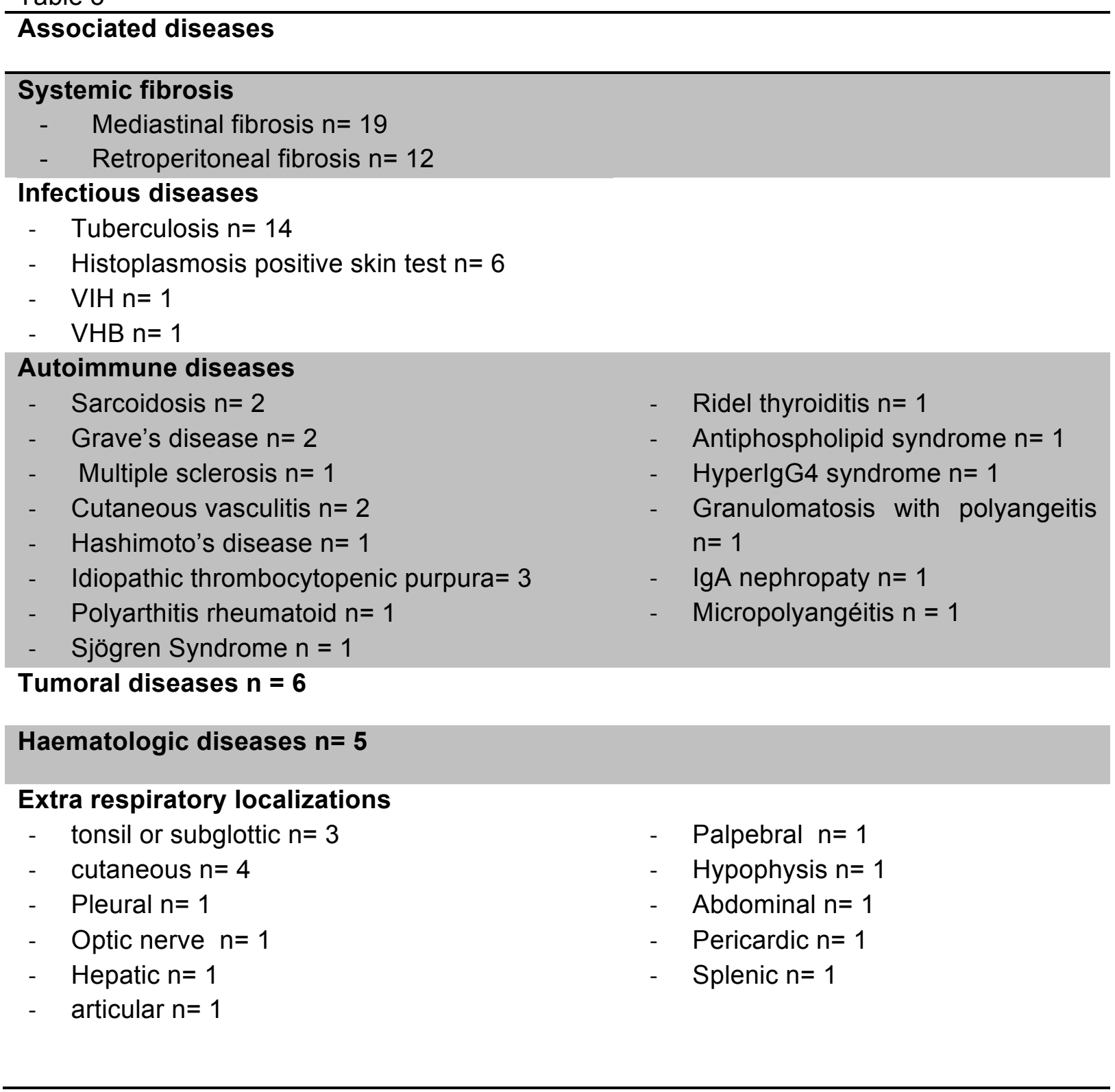




\begin{tabular}{llll}
\hline & & Recurrence & No recurrence \\
\hline $\begin{array}{l}\text { Complete } \\
\text { Surgery }\end{array}$ & 14 & 5 & 9 \\
\hline
\end{tabular}

\begin{tabular}{|c|c|c|c|c|c|}
\hline & \multirow{2}{*}{$\mathbf{N}$} & \multicolumn{3}{|c|}{ CT scan or $\mathrm{X}$ ray evaluation } & \multirow[t]{2}{*}{ p } \\
\hline & & Stable & Worsening & improvement & \\
\hline $\begin{array}{l}\text { No treatment (first } \\
\text { line) }\end{array}$ & 46 & $29(63 \%)$ & $15(32.6 \%)$ & $2(4.4 \%)$ & \\
\hline $\begin{array}{l}\text { Corticosteroids } \\
\text { (first or second } \\
\text { line) }\end{array}$ & 19 & $8(42.1 \%)$ & $3(15.8 \%)$ & $8(42.1 \%)$ & 0,0006 \\
\hline \multicolumn{6}{|l|}{$\begin{array}{l}\text { Other therapeutic } \\
\text { (second line) }\end{array}$} \\
\hline $\begin{array}{l}\text { IVIG, plasmatic } \\
\text { exchange, } \\
\text { corticosteroids }\end{array}$ & 1 & 1 & 0 & 0 & \\
\hline $\begin{array}{l}\text { Cyclophosphamid, } \\
\text { corticosteroids }\end{array}$ & 2 & 0 & 0 & 2 & \\
\hline $\begin{array}{l}\text { Vincristin, } \\
\text { cyclophosphamide, } \\
\text { corticosteroids }\end{array}$ & 1 & 0 & 0 & 1 & \\
\hline $\begin{array}{l}\text { Melphalan, } \\
\text { vincristine, } \\
\text { corticosteroids }\end{array}$ & 1 & 0 & 0 & 1 & \\
\hline
\end{tabular}




\section{Acknowledgment:}

For translation of articles and bibliography search : Mehdi Gharbi, Harika Salepcioglu, Toshikado Kaneta, Yojiro Shibata, Young Jiang 


\section{References}

[1] Benfield JR, Harrison RW, Moulder PV, Lyon ES, Graff PW. Bilateral nodular pulmonary granulomas and retroperitoneal fibrosis. JAMA. 1962; 182: 579-81.

[2] Engleman P, Liebow AA, Gmelich J, Friedman PJ. Pulmonary hyalinizing granuloma. American review of respiratory disease. 1977; 115: 997-1008

[3] Nazek M, Mandybur TI, Sawaya R. Hyalinizing plasmacytic granulomatosis. Am J Surg pathol. 1988; 12(4):308-313

[4] Ulbright TM, Katsenstein ALA. Solitary necrotizing granulomas of the lung. Am J Surg Pathol. 1980; 4: 13-28

[5] Peng M, Xu WB, Shi JH, Cai BQ, Tian XL, Liu T et al. The diagnostic value of CT-guided percutaneous needle lung biopsy in diffuse parenchymal lung diseases. Zhonghua Jie $\mathrm{He} \mathrm{He}$ Hu Xi Za Zhi. 2012;35(3):171-5

[6] Khalifa LG, Schimmel DH, Gamsu G. Multiple chronic benign pulmonary nodules. Radiology. 1976; 121: 275-9

[7]Drasin H, Blume MR, Rosenbaum EH, Klein H. Pulmonary hyalinizing granulomas in a patient with malignant lymphoma, with development nine years later of multiple myeloma and systemic amyloidoisis. Cancer. 1979; 44: 215-20.

[8] Schlosnagle DC, Check IJ, Whitaker Sewell C, Plummer A, York RM, Hunter RL. Immunologic abnormalities in two patients with pulmonary hyalinizing granuloma. Am J Clin Pathol. 1982; 78: 231-5

[9] Dent RG, Godden D, Stovin PGI, Stark JE. Pulmonary hyalinizing granuloma in association with retroperitoneal fibrosis. Thorax. 1983; 38: 955-6

[10]Chalaoui J, Grégoire P, Sylvestre J, Lefebvre R, Amyot R. Pulmonaary hyalinizing granuloma : a cause of pulmonary nodules. Radiology. 1984; 152: 23-6

[11] Guccion JG, Rohatgi PK, Saini Nirmal. Pulmonary hyalinizing granuloma. Electron microscopic and immunologic studies. Chest. 1984; 85(4): 571-3)

[12] Maijub AG, Giltman LI, Verner JL, Peace RJ. Pulmonary hyalinizing granuloma. Annals of allergy.1984; $54: 227-9$

[13]Cerrina J, Grateau G, Piette JC, Godeau P, Merlier M. Medistinite fibreuse dite idiopathique. Chirurgie. 1986; 112 (5) : 367-78 
[14] Youssem SA, Hochholzer L. Pulmonary hyalinizing granuloma. Am J Clin Pathol. 1987; 87: 1-6

[15] Ikard RW. Pulmonary hyalinizing granuloma. Chest. 1988; 93(4): 871-2

[16] Gans SJM, Van Der Elst, Straks W. Pulmonary hyalinizing granuloma. Eur respir J. 1988; 1: 389-91

[17] Zafisaona G, Clary C, Meseure D. Granulome pulmonaire hyalinizant. A propos d'un cas. Sem hop Paris. 1988; 64 (44): 2851-5

[18] Macedo EV, Adolph J. Pulmonary hyalinizing granulomas. Journal de l'association canadienne des radiologists. $1985 ; 36: 66-7$

[19]case records of the Massachusetts general hospital, 6-1989. The new England journal of medicine. 1989; 320 (6): 380-9

[20] Van Custem O, Ledent C, Mairesse M. Le granulome hyalinisant du poumon. Rev Mal Respir. 1990; 7 : 279-82

[21] Dominguez P, Sotelo T, Varela, Perez P. Multiple hyalinizing granuloma of the lung. Rev Clin Esp. 1990; 186 (6): 307-8

[22] Eschelman DJ, Blickman JG, Lazar HL, O’keane JC, Schechter M. Pulmonary hyalinizing granuloma: a rare cause of solitary pulmonary nodule. J Thorac Imaging. 1991; 6 (2): 54-6

[23] Kuramochi S, Kawai T, Yakumaru K, Mikata A. Torikata C, Kasuga Y et al. Multiple pulmonary hyalinizing granulomas associated with systemic idiopathic fibrosis. Acta Pathol Jpn. 1991; 41: 375-82.

[24] Patel Y, Ishukawa S, MacDonnell KF. Pulmonary hyalinizing granuloma presenting as multiple cavitary calcified nodules. Chest. 1991; 100: 1720-1.

[25] Lhote F, Chapelon C, Piette JC, Andrien JM, Chomette G, Godeau P. Pulmonary hyalinizing granuloma. 2 case reports. Rev Mal Resp. 1991; 8: 246-8.

[26] Anazawa Y, Nagai H, Motomiya M, Isawa T, Saito Y, Takahashi T et al. A case of pulmonary hyalinizing granuloma. Tohoku J Exp Med. 1992; 167: 39-45

[27] Atagi S, Sakatani M, Akira M, Yamamoto S, Ueda E. Pulmonary hyalinizing granuloma with castleman's disease. Internal Medicine. 1994; 33: 689-91

[28] John PG, Rahman J, Payne CB. Pulmonary hyalinizing granuloma: an unusual association with multiple sclerosis. South Med J. 1995 Oct;88(10):1076-7 
[29] Kido M, Kaiki A, Nagata N, Manabe H, Iwata Y. A case of pulmonary hyalinizing granuloma with its occupational history of dust exposure. J UOEH. 1995; 17(1): 31-7

[30] Banaschak S, Muller KM. The differential diagnosis of multiple pulmonary nodules pulmonary hyalinizing granulomas. Pneumologie. 1996; 50: 211-4

[31] Ramirez J, Mehta JB, Taylor RA, Byrd RP, Roy TM. Symptomatic pulmonary hyalinizing granuloma. Southern medical journal. 1998; 91(9): 867-9

[32] Gorini M, Forloni F, Pezzoli A, Pezzica E. Pulmonary hyalinizing granuloma. Limited form of wegener's granulomatosis? Ann Ital Med Int. 1998; 13: 176-9

[33] Kadoyama C, okosuka T, Otsuji M, Suzuki M. Pulmonary hyalinizing granuloma diagnosed by thoracoscopy. Nihon Kokyuki Gakkai Z asshi. 1999; 37(6): 481-4

[34] Russel AFR, Suggit RIC, Kazzi JC. Pulmonary hyalinizing granuloma : a case report and literature review. Pathology. 2000; 32: 290-3

[35] Laraki R, Wechsler B, Bourgeon B, Wechsler J, Charlotte F, Piette JC. Le granulome pulmonaire hyalinisant: à propos de deux observations originals avec localization cervicofaciale et orbitaire. Rev Med Interne. $2001 ; 22$ : 284-91

[36] Ren Y, Raitz EN, Lee KR, Pingleton SK, Tawfik O. Pulmonary small lymphocytic lymphoma (mucosa-associated lymphoid tissue type) associated with pulmonary hyalinizing granuloma. Chest. 2001; 120(3): 1027-30

[37] Rios Zambudio A, Roca Calvo J, Torres Lanzas J, Parrilla Paricio P. Granuloma hialinizante multiple pulmonar. Medicina clinica. 2001; 116 (4): 157-9

[38] Yang J, Liang Y, Liao S. Pulmonary hyalinizing granuloma : a case report and a review of the literature. Zhongua Jie He He Hu Xi Za Zhi. 2001; 24(6): 369-70

[39] Fujishama N, Takada T, Moriyama H, Saito Y, Suzuki E, Yoshiya K et al. Pulmonary hyalinizing granuloma with massive infiltration of lymphocytes. Nihon kokyuki gakkai zasshi. 2001; 39 (12): 924-9

[40] Hashimoto S, Fujii W, Takahashi T, Shiroshita K, Sakurai T, Ueda T et al. Pulmonary hyalinizing granuloma with hydrinephrosis. Internal medicine. 2002 ; 41 : 463-6

[41] Wierzbsicka M, Kus J, Langfort Renata. A case of multiple pulmonary granuloma. Pneumonol alergol pol. 2002; 70 (1-2): 97-101

[42]Khilnani GC, Kumar A, Datta Gupta S, Surendranath A, Sharma S. J Assoc Physicians India. 2003; 51: 519-21 
[43]Gossot D, Fromont G, Galetta D, Debrosse D, Grunenwald D. Granulome pulmonaire hyalinisant avec fibrose médiastinale: une cause rare de dysphagie. Annales de chirurgie. $2003 ; 128: 622-5$

[44] Pinckard JK, Rosenbluth DB, Patel K, Dehner LP, Pfeifer JD. Pulmonary hyalinizing granuloma associated with aspergillus infection. International journal of surgical pathology. 2003; 11 (1): 39-42 [45] Wheen LC, Taylor GB. Pulmonary haylinizing granuloma: an airwayacquired aetiology? Pathology. 2004; 36 (6): 583-5

[46] Lvovsky D, Rosman J, Iliescu M. Pulmonary hyalinizing granuloma presenting as bilateral dense apical masses. Chest. 2004; 126 (4): 950S-1S

[47]Hantous-Zannad S, Zidi A, Boussema F, Mestiri I, Ben Hassine R, Cherif O et al. Le granulome pulmonaire hyalinisant: à propos de deux cas. J radiol. 2004 ; 85 : 1074-6

[48] Shinohara T, Kanko T, Miyazawa, Nakatani Y, Nishiyama H, Shoji A et al. Pulmonary hyalinizing granuloma with laryngeal and subcutaneous involvement : report of a case successfully treated with glucocorticoids. internal medicine; 200443 (1) 69-73

[49] O'reilly KMA, Boscia JA, Kaplan KL, Sime PJ. A case of steroid responsive pulmonary hyalinizing granuloma: complicated by deep venous thrombosis. Eur Respir J. 2004; 23: 9546.

[50] Esme H, Ermis SS, Fidan F, Unlu M, Dilek FH. A case of pulmonary hyalinizing granuloma associated with posterior uveitis. Tohoku J Exp Med. 2004; 204: 93-7.

[51] Potat S, Nicholson AG, Fisher C, Harmer C, Moskovic E, Murday VA et al. Pulmonary masses presenting 11 years after abdominal surgery. Respiration. 2004; 71: 295-7

[52] Vezzani G, Cavazza A, Rosi G, Pasquinelli G, Avanzini P, Asioli S et al. Pulmonary hyalinizing granuloma. Clinicopathologic study of 2 cases, with some original ultrastructural observations and review of the literature. Pathologica.2004; 96: 25-8

[53] Satti MB, Batouk AA, Abdelaziz MM, Ahmad MF, Abdelall MA. Pulmonary hyalinizing granuloma. Bilateral pulmonary nodules associated with chronic idiopathic thrombocytopenic purpura. Saudi Med J. 2005; 26 (9): 1459-63

[54] Agrawal D, Deshpande R, Maheshwari S, Patel A, Udwadia ZF. Pulmonary hyalinizing granuloma with ureteric fibrosis: a case report and review of relevant literature. Indian $\mathrm{J}$ Chest Dis Allied Sci. 2006; 48: 283-5 
[55] Basoglu A, Findik S, Celik B, Yildiz L. Pulmonary hyalinizing granuloma mimicking lung carcinoma. Thorac Cardiov Surg. 2006; 54: 276-88

[56] Fidan A, Ocal Z, Caglayan B, Dogusoy I, Gumrukcu G. An unusual cause of pulmonary nodules: pulmonary hyalinizing granuloma with recurrence. Respiratory Medicine Extra. 2006; 2: 112-5

[57] Ucvet A, Tozum H, Gursoy S, Gulle AA, Yaldiz S, Aydogdu Dinc Z. Pulmonary hyalinizing granuloma mimicking pulmonary carcinoma. Tuberkuloz ve toraks dergisi. 2006; 54 (1): 71-4

[58] Wang WZ, Liu HR, Guo LN. Pulmonary hyalinizing granuloma: report of 2 cases. Zhomghua bing li xue za zhi. 2006; 35 (8): 505-7

[59] Colen RR, Nagle JA, Wittram C. Radiologic-pathologic conference of the Massachusetts general hospital. Am J Roentgenol. 2007; 188: w115-6

[60] Winger DI, Spiegler P, Trow TK, Goyal A, Yu H, Yung E et al. Radiology-pathology conference: pulmonary hyalinizing grauloma associated with lupus-like anticoagulant and morvan's syndrome. Clinical Imaging. 2007; 31: 264-8

[61] Na KJ, Song SY, Kim JH, Kim YC. Subpleural pulmonary hyalinizing granuloma presenting as a solitary pulmonary nodule. Journal of thoracic oncology. 2007; 2(8): 777-9

[62] Young AS, Binkovitz LA, Adler BH, Nicol KK, Rennebohm RM. Pulmonary hyalinizing granuloma and retroperitoneal fibrosis in an adolescent. Pediatr radiol. 2007; 37: 91-5 [63] Shibata Y, Kobayashi T, Hattori Y, Matsui O, Gabata T, Tamori S et al. High-resolution CT findings in pulmonary hyalinizing granuloma. J Thorac Imaging. 2007; 22 (4): 374-7

[64] Chia J, Tapson V. Pulmonary hyalinizing granuloma presenting with hemoptysis and hilar mass. Chest. 2007; 132 (4 supplement): 707 S

[65] Liu T, Kyrollos M, Kravcik S. Pulmonary hyalinizing grnuloma in HIV/AIDS. Can J Infect Dis Med Microbiol. 2007; 18 (5): 305-7

[66] Ben Ghorbel I, Ennaifer R, Haouet S, Khanfir M, Lamloum M, Miled M et al. Pulmonary hyalinizing granuloma revealed by a pituitary gland diffusion. La revue de medicine interne. 2008; 29: 54-7

[67]Preuss J, Woenckhaus C, Thierauf A, trehler M, Madea B. Non-diagnosed pulmonary hyalinizing granuloma (PHG) as a cause of sudden unexpected death. Forensic science international. 2008; 179: e51-5 
[68]Xu Z, Bethune D, Manos D, Doyle A, Henteleff H, Johnston M et al. Pulmonary hyalinizing granuloma. Journal of peking university. 2009; 41 (4): 463-8

[69] Khalid I, Stone C, Kvale P. A unique case of pulmonary hyalinizing granuloma associated with FDG-avid PET scan and deep venous thrombosis. J Bronchol Pulmonol. 2009; 16(2): 108-11

[70] Kaneta T, Saito A, Akiyama T, Takahashi Y, Kudou K. A case of pulmonary hyalinizing granuloma with high-grade uptake on FDG-PET mimicking metastatic lung cancer. Nihon Kokyuki Gakkai Zasshi. 2009; 47 (10): 953-9

[71] Arruda GDS, Carvalho PCR, Andrade MPG, Cusmanich MC, Bandeira G, Tozaki FSP. Recurrent pulmonary hyalinizing granuloma. J Bras Pneumol. 2010; 36 (5): 662-5

[72] Brandao V, Marchiori E, Zanetti G, Abdalla G, Ventura N, Constantino CL et al. Hyalinizing granuloma: an unusual case of a pulmonary mass. Case reports in medicine. 2010 Epub 2010 jun 14

[73] Lien CT, Yang CJ, Yang SF, Chou SH, Huang MS. Pulmonary hyalinizing granuloma mimicking multiple lung metastases. J Thorac Imaging. 2010; 25: w36-9

[74] Boutayeb L, Gen-hijos M, Mayayo E. Pulmonary hyalinizing granuloma. Arch Bronconrumol. 2012; 48 (9): 342-6

[75] Chapman EM, Gown A, Mazziotta R, Churg A. Pulmonary hyalinizing granuloma with associated elevation in serum and tissue IgG4 occuring in a patient with a history of sarcoidosis. Am J Surg Pathol. 2012; 36: 774-8

[76] Rahatullah A, Waheed Z, Khan JA, Nasir-ud-Din. Pulmonary hyalinizing granuloma: a rare pulmonary disorder. J Pak Med Assoc. 2012; 62 (5): 493-5

[77] Matsuoka K, Imanishi N, Matsuoka T, Nagai S, Ueda M, Miyamoto Y. Pulmonary Hyalinizing Granuloma Detected in a Family Member after Confirmation of Tuberculosis in His Father. Ann Thorac Cardiovasc Surg. 2013 Jul 31. [Epub ahead of print]

[78] Coleman C, Nassar A, McComb B. Pulmonary Hyalinizing Granuloma Associated with Idiopathic Thrombocytopenic Purpura. J Cin Imaging Sci 2014;4-8

[79] Ussavarungsi K, Khoor A, Jolles HI, Mira-Avendano I. A 40-Year-Old Woman With Multiple Pulmonary Nodules. CHEST. 2014; 146(6): e198-e203

[80] Westhoff M, Litterst P, Albert M, Welim B. Pulmonary Hyalinizing Granuloma. Pneumologie. 2015; 69:30-5 
[81] Duzgun N, Kurtipek E, Esme H, Karanis MIE, Tolu I. Pulmonary Haylinizing Granuloma Mimicking Metastatic Lung Cancer. Case reports in Pulmonology. 2015

[82] Rodriguez-Muguruza S, Holgado S, Olivé A. Pulmonary Hyalinizing granuloma associated with Sjögren syndrome and ANCA MPO vasculitis. Joint Bone Spine. 2015; 82: 66-73

[83] Ceresini G, Urban ML, Corradi D and al. Association between idiopathic retroperitoneal fibrosis and autoimmune thyroiditis: a case-control study. Autoimmun Rev. 2015; 14: 16-22

[84] Doria A, Sarzi-Puttini P, Shoenfeld Y. Infections, rheumatism and autoimmunity: the conflicting relationship between human and their environnement. Autoimmun Rev. 2008, doi:10.1016/j;autrev.2008.07.014 
